Review

\title{
E2 ubiquitin-conjugating enzymes in cancer: Implications for immunotherapeutic interventions
}

\author{
Seyed Mohammad Hosseini ${ }^{\mathrm{a}, \mathrm{b}}$, Isobel Okoye ${ }^{\mathrm{c}}$, Mitra Ghasemi Chaleshtari ${ }^{\mathrm{d}}$, Bita Hazhirkarzar ${ }^{\mathrm{e}}$, \\ Javad Mohamadnejad $^{\text {b }}$, Gholamreza Azizi ${ }^{\mathrm{f}}$, Mohammad Hojjat-Farsangi ${ }^{g, h}$, Hamed Mohammadi ${ }^{\mathrm{f}}$, \\ Siamak Sandoghchian Shotorbani ${ }^{\mathrm{a}}$, Farhad Jadidi-Niaragh $\mathrm{i}^{\mathrm{i}, \mathrm{j}, *}$ \\ ${ }^{a}$ Drug Applied Research Center, Tabriz University of Medical Sciences, Tabriz, Iran \\ ${ }^{\mathrm{b}}$ Department of Life Science Engineering, Faculty of New Sciences and Technologies, University of Tehran, Tehran, Iran \\ ${ }^{\mathrm{c}}$ Department of Dentistry, Faculty of Medicine and Dentistry, University of Alberta, Edmonton, T6G 2E1, Canada \\ ${ }^{\mathrm{d}}$ Department of Clinical Biochemistry, Faculty of Medicine, Yasuj University of Medical Sciences, Yasuj, Iran \\ ${ }^{\mathrm{e}}$ Russell H. Morgan Department of Radiology and Radiological Sciences, Johns Hopkins University School of Medicine, Baltimore, MD 21287, USA \\ ${ }^{\mathrm{f}}$ Non-Communicable Diseases Research Center, Alborz University of Medical Sciences, Karaj, Iran \\ ${ }^{\mathrm{g}}$ Bioclinicum, Department of Oncology-Pathology, Karolinska Institute, Stockholm, Sweden \\ ${ }^{\mathrm{h}}$ The Persian Gulf Marine Biotechnology Medicine Research Center, Bushehr University of Medical Sciences, Bushehr, Iran \\ ${ }^{\mathrm{i}}$ Immunology Research Center, Tabriz University of Medical Sciences, Tabriz, Iran \\ ${ }^{\mathrm{j}}$ Department of Immunology, Faculty of Medicine, Tabriz University of Medical Sciences, Tabriz, Iran
}

A R T I C L E I N F O

\section{Keywords:}

E2 conjugating enzymes

Ubiquitin

Cancer

Immunotherapy

\begin{abstract}
A B S T R A C T
Despite the medical advances of the 21st century, the incidence of cancer continues to increase and the search for a universal cure remains a major health challenge. Our lack of understanding the complex pathophysiology of the tumor microenvironment has hindered the development and efficiency of anti-cancer therapeutic strategies. The tumor microenvironment, composed of multiple cellular and non-cellular components, enables tumorpromoting processes such as proliferation, angiogenesis, migration and invasion, metastasis, and drug resistance. The ubiquitin-mediated degradation system is involved in several physiologic processes including cell cycling, signal transduction, receptor downregulation, endocytosis and transcriptional regulation. Ubiquitination includes attachment of ubiquitin to target proteins via E1 (activating), E2 (conjugating) and E3 (ligating) enzymes. Several studies have shown that E2 enzymes are dysregulated in variety of cancers. Multiple investigations have demonstrated the involvement of E2s in various tumor-promoting processes including DNA repair, cell cycle progression, apoptosis and oncogenic signaling. E2 enzymes consist of 40 members that facilitate ubiquitinsubstrate conjugation thereby modulating the stability and interaction of various proteins. As such, E2s are potential biomarkers as diagnostic, prognostic and therapeutic tools. In this review, we discuss the role of E2s in modulating various types of cancer.
\end{abstract}

\section{Introduction}

The uncontrolled proliferation of cells, which leads to rapid growth of disorganized tumor tissue is known as cancer [1,2]. Cancer is one of the main causes of mortality in developed countries, and the developing world, to a lesser extent. Modified human lifestyles during the last decades including physical inactivity, poor dietary habits and substance abuse have increased cancer risks [3-6]. Accordingly, increased prevalence of colorectal, breast, lung, and prostate cancers has been observed in developed countries. On the other hand, some infection-related cancers such as cervical, stomach, and liver cancers are increased in less developed countries [7]. Multiple cellular and non-cellular components are present in tumor region, which forms the tumor microenvironment $[8,9]$. The nature of the tumor microenvironment in tumor progression and modulation of cancer immunotherapy has been extensively demonstrated [10]. Several non-cancerous cellular participants form the tumor microenvironment including immune and inflammatory cells, bone marrow derived cells, cancer associated fibroblasts (CAFs), extracellular matrix, pericytes, and endothelial cells. The interaction of cancer cells with this complex network enhances tumor growth and progression and induces drug resistance [11,12]. The tumor microenvironment can also promote the induction of cancer stem cells,

\footnotetext{
* Corresponding author at: Immunology Research Center, Tabriz University of Medical Sciences, Tabriz, Iran.

E-mail address: jadidif@tbzmed.ac.ir (F. Jadidi-Niaragh).
} 


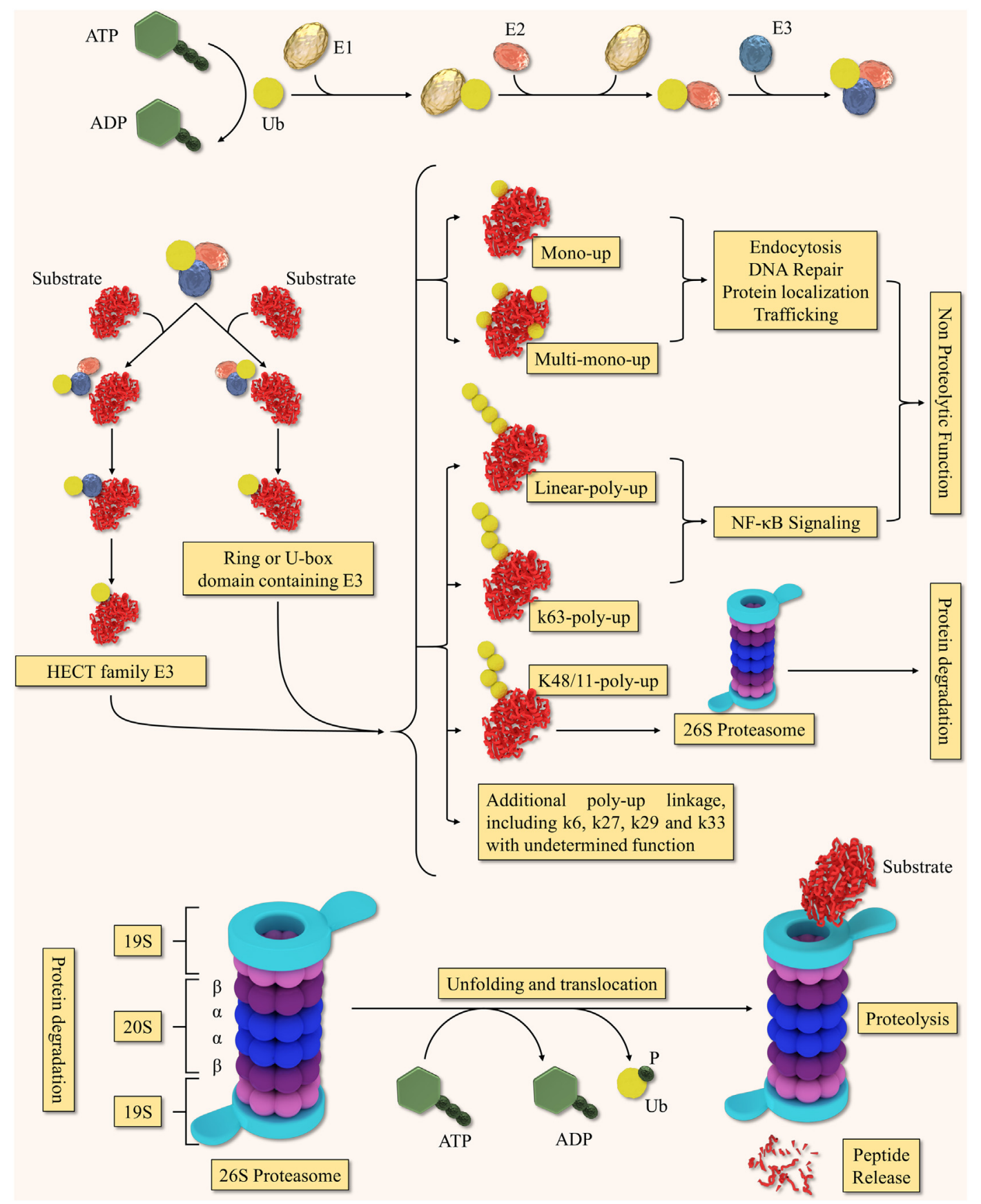

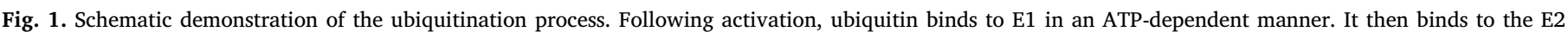

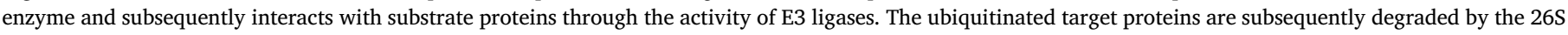
proteasome complex

which support tumor recurrence [13,14]. Although several efforts have focused on understanding tumor immuno-biology and identifying new therapeutic strategies, current treatments are unable to counter a variety of tumour types. This is due partly to the ability of cancer cells to outsmart anti-tumour mechanisms by both intrinsic tumour factors and the extrinsic support of the tumor microenvironment (Fig. 1) $[15,16]$. These intrinsic and extrinsic pressures promote tumor growth, drug resistance, the development of cancer stem cells, cancer recurrence and metastasis. Intrinsic mechanisms, which are mainly fueled by mutations, include dysregulated apoptosis, drug efflux, loss of specific oncogenes, modified metabolism, development of stemness, and enhanced DNA repair. On the other hand, extrinsic pressure includes several mechanisms driven by multiple cellular and non-cellular components of the tumor microenvironment [17-21]

It has recently been shown that enzymes involved in ubiquitination, which leads to proteasome-mediated protein degradation, are critically involved in tumorigenesis. These enzymes include E1 (activating), E2 (conjugating), and E3 (ligating) enzymes, which facilitate ubiquitination. Amongst them, the E2-conjugating enzymes have been proposed as pivotal factors, which are dysregulated in cancer settings and contribute to various tumor-promoting processes including DNA repair, apoptosis, cell cycle progression, and oncogenic signaling pathways. Therefore, they can be considered as reliable prognostic and diagnostic indicators, which can be targeted as part of a cancer therapeutic strategy. In this review, we will discuss the intricacies of E2-conjugating enzymes and their role in cancer progression. 


\section{UBE2s}

The highly conserved protein, ubiquitin (UB; containing 76-amino acids with a molecular weight of $8.5 \mathrm{kDa}$ ) is present in all eukaryotic cells. UB can regulate the stability and biological functions of its substrates by ubiquitination, whereby UB covalently conjugates with target proteins in a reversible manner [22]. During ubiquitination, UB proteins bind substrate proteins through the coordinated activity of three enzymes: E1 (activating), E2 (conjugating) and E3 (ligating) enzymes. For ubiquitination, UBE1-activating enzymes first bind and activate UB via ATP consumption in order to form the E1-Ub conjugate. This is followed by the UBE2-conjugation enzyme, which binds to a thioester group of UB through the cysteine residue. The conjugation of specific lysine residues of the protein substrate with glycine on UB is finally facilitated by UBE3 ligases [23]. The class of isopeptidases, known as deubiquitinases, can remove UB chains from substrate proteins [24].

Ubiquitination, as one of the most pivotal post-transcriptional mechanisms, plays a key role in multiple physiological processes [25]. Although ubiquitination has been known as protein degradation tool, there is evidence that it contributes to various processes including transcription, endocytosis, DNA repair, intracellular trafficking, plasma membrane receptor recycling, angiogenesis and inflammatory signaling [26]. This functional diversity may be partly due to presence of various lysine residues (K) in UB including K6, 11, 27, 29, 33, 48, and 63, which mediate formation of the polymeric chain [27]. Accordingly, dysregulation of ubiquitination has been associated with several disorders such as neurodegenerative diseases, autoimmune disorders, muscle atrophy, diabetes, and cancer. Among the ubiquitination-involved enzymes, E2s play a key role in various types of cancer and are comprised of four different categories. Class I E2s have only the UBC domain, whereas class II and III E2s contain additional $\mathrm{N}$ and $\mathrm{C}$ terminal domains, respectively. Class IV E2s contain both $\mathrm{N}$ and C domains [28]. Table 1 shows the main E2 enzymes with their biological functions and associated diseases (Fig. 2).

\section{UBE2s in cancer}

Several investigations have indicated that all ubiquitination-associated enzymes including E1, E2, and E3 promote tumorigenesis, which implies that they may be suitable targets for anti-cancer therapies. However, the design and development of selective inhibitors, which can block protein-protein interactions is problematic. Among the ubiquitination-associated enzymes, E2s have emerged as potent mediators of tumorigenesis. The E2 family is comprised of 40 members, which modulate the stability of proteins and ubiquitination through the conjugation of UB to target proteins [29]. Dysregulation of various E2s has been reported in several cancer types. Moreover, multiple E2 enzymes can drive cell cycle progression, DNA repair, and stimulation of oncogenic signaling pathways during malignant transformation. Therefore, E2s can be considered as worthy cancer related biomarkers for diagnosis, prognosis and therapeutic targeting. Despite advances in the identification of the biological properties of E2 enzymes, a limited number of E2-selective inhibitors have been developed $[28,30]$.

\subsection{UBE2A in cancer}

UBE2A, a RAD6 yeast homolog HR6A protein, promotes cell cycle progression by binding with the RAD18 ubiquitin ligase, which leads to induction of poly-ubiquitination process. UBE2A is a critical factor in tumorigenesis. Dysregulated expression of cyclin dependent kinases (CDKs), which are key modulators of cell cycle, can affect UB proteasomal degradation and trigger cancer induction [31,32]. Blockade of UBE2A interaction with RAD18 has been identified as potential cancer therapeutic strategy [33].

\subsection{UBE2C in cancer}

UBE2C, located at chromosome 20q13.12, consists of eight isoforms with a molecular weight of $19 \mathrm{kDa}$ and composed of 179 amino acids. UBE2C is expressed variably during cell cycle progression, which correlates with its role in cell cycle regulation [3]. UBE2C is also involved in the regulation of mitosis and targeted degradation of short-lived proteins [34]. The overexpression of UBE2C has been associated with various cancer types, and correlates with poor prognosis and drug resistance [35-38]. The overexpression of UBE2C by various cancer cell lines compared to normal cells has been demonstrated [39]. Other investigations have demonstrated that UBE2C plays a role in the expansion and invasion of cancer cells [40,41], with overexpression correlating with poor prognosis of pancreas, lung, breast, skin and thyroid cancers $[3,41-45]$.

Increased expression of UBE2C has also been observed in tumours compared to normal tissue of breast cancer patients [46], which was associated with poor prognosis. However, no correlation between the expression of UBE2C and the clinical manifestation of breast cancer subtypes has been observed. UBE2C can also promote drug resistance in cancer cells, as blockade of UBE2C led to enhanced breast cancer cell sensitivity to doxorubicin [47]. Therefore, the expression of UBE2C can serve as a biomarker of doxorubicin sensitivity in breast cancer patients.

BRCA1 can also act as a negative UBE2C regulator [48,49]. Accordingly, blockade of BRCA1 expression was associated with upregulation of UBE2C. The interaction of BRCA1 with other UBE2s has also been demonstrated [38].

The upregulation of UBE2C has also been associated with human intestinal-type gastric cancer. Furthermore, silencing of UBE2C in these cells correlated with the interruption of cell cycling at the G2/M stage. On the other hand, overexpression of this enzyme led to enhanced ERK signaling and proliferation of cancer cells. Interestingly, blockade of ERK signaling by its inhibitor, U0126, reversed UBE2C-induced oncogenic phenotypes. Overexpression of UBE2C induces chromosomal instability, perturbs the cell cycle and indicates poor prognosis of gastric cancer [3].

High expression levels of UBE2C have also been observed in hepatocellular carcinoma, which was associated with advanced disease and low survival rates. Consequently, silencing UBE2C led to reduced expansion, invasion, and migration of hepatocellular carcinoma cells. This strategy also enhanced the sensitivity of these cells to cytotoxicity associated with chemotherapeutics such as 5-fluorouracil, Adriamycin, and sorafenib. Therefore, UBE2C can also be considered as potential prognosis factor and therapeutic target in hepatocellular carcinoma [50].

It has been proposed that miR-495 regulates cisplatin resistance in non-small cell lung cancer (NSCLC) partly by modulating UBE2C. Moreover, lung cancer biopsies express low levels of miR-495. Higher expression levels of UBE2C have also been observed in cisplatin-resistant NSCLC cells, which was associated with high proliferation, invasion and drug resistance. Accordingly, silencing UBE2C led to upregulation of E-cadherin and downregulation of vimentin. UBE2C can directly bind to the 5'-UTR of the genes that confer drug-resistance such as ERCC1 and ABCG2. On the other hand, miR-495 can suppress ERCC1 and ABCG2 by regulating UBE2C. Therefore, the miR-495/UBE2C/ ERCC1/ABCG2 axis can suppress cisplatin resistance partly by hampering epithelial to mesenchymal transition (EMT), and downregulating the expression of of drug resistance associated genes by NSCLC cells [51].

Upregulation of UBE2C has also been detected in rectal carcinoma. Moreover, silencing this factor by siRNA interference was associated with cancer cell apoptosis and reduced proliferation, invasion, and colony formation. Similarly, downregulation of UBE2C in a xenograft tumor model led to tumor regression. Interestingly, miR-381 modulates the expression of UBE2C in rectal carcinoma [52]. 
Table 1

Main ubiquitin E2 enzymes and their biological and pathological functions.

\begin{tabular}{|c|c|c|c|}
\hline Name & Classes & Diseases & Biological roles \\
\hline UBE2A & Class I & $\begin{array}{l}\text { Cancer } \\
\text { Cognitive disability } \\
\text { Skeletal } \\
\text { muscle atrophy } \\
\text { novel X-linked mental retardation (XLMR) }\end{array}$ & $\begin{array}{l}\text { DNA repair } \\
\text { Transcription regulation }\end{array}$ \\
\hline UBE2B & Class I & $\begin{array}{l}\text { Idiopathic azoospermia } \\
\text { Skeletal muscle atrophy }\end{array}$ & $\begin{array}{l}\text { DNA repair } \\
\text { Cell cycle progression Spermatogenesis }\end{array}$ \\
\hline UBE2C & Classes II & Cancer & Cell cycle progression \\
\hline UBE2D1 & Class I & Cancer & $\begin{array}{l}\text { DNA repair } \\
\text { Iron transport }\end{array}$ \\
\hline UBE2D2 & Class I & Parkinson disease & $\begin{array}{l}\text { DNA repair } \\
\text { Parkin mediated mitophagy }\end{array}$ \\
\hline UBE2D3 & Class I & Parkinson disease Infectious disease & $\begin{array}{l}\text { DNA repair } \\
\text { NF- } \mathrm{KB} \text { signaling }\end{array}$ \\
\hline UBE2D4 & Class I & Cancer & DNA repair \\
\hline UBE2E1 & Classes II & $\begin{array}{l}\text { Cancer } \\
\text { Sjogren's syndrome }\end{array}$ & PTEN ubiquitination and transport \\
\hline UBE2E2 & Classes II & Diabetes & Glucose homeostasis \\
\hline UBE2E3 & Classes II & Liddle's syndrome & $\begin{array}{l}\text { NRF2 transport } \\
\text { Epithelial } \mathrm{Na}+\text { transport }\end{array}$ \\
\hline UBE2F & Classes II & Cancer & Protein neddylation \\
\hline UBE2G1 & Class I & Skeletal muscle atrophy & Skeletal muscle protein regulation \\
\hline UBE2G2 & Class I & $\begin{array}{l}\text { Cancer } \\
\text { Sjogren's syndrome }\end{array}$ & ER-associated degradation (ERAD) \\
\hline UBE2H & Classes III & Autism & Histone and cytoskeleton ubiquitination \\
\hline UBE2I & Class I & Cancer & SUMO E2 \\
\hline UBE2J1 & Classes III & $\begin{array}{l}\text { Sjogren's syndrome } \\
\text { Skeletal muscle atrophy }\end{array}$ & $\begin{array}{l}\text { ERAD } \\
\text { Spermiogenesis }\end{array}$ \\
\hline UBE2J2 & Classes III & Cancer & ERAD \\
\hline UBE2K & Classes III & Huntington Disease & Aggregate formation of expanded polyglutamine \\
\hline UBE2L3 & Classes I & $\begin{array}{l}\text { Lupus erythematosus and rheumatoid } \\
\text { arthritis }\end{array}$ & proteins \\
\hline UBE2L6 & Classes I & Cancer & NF- $\mathrm{kB}$ signaling \\
\hline UBE2M & Classes II & Hypertension & Protein neddylation \\
\hline UBE2N & Classes I & Parkinson disease & DNA repair \\
\hline UBE2O & Class IV & $\begin{array}{l}\text { Cancer } \\
\text { Microcytic anemia }\end{array}$ & $\begin{array}{l}\text { AMPK } \alpha 2 \text { ubiquitination and degradation } \\
\text { MLL ubiquitination and Degradation Erythroid differentiation and proteostasis Adipocyte differentiation } \\
\text { Endocytic trafficking }\end{array}$ \\
\hline UBE2Q1 & Classes II & Cancer & $\beta$-catenin-EGFR-PI3K-AKT-mTOR signaling \\
\hline UBE2Q2 & Classes II & $\begin{array}{l}\text { Cancer } \\
\text { Chronic kidney disease }\end{array}$ & Apoptosis \\
\hline UBE2R1 & Classes III & Parkinson disease & Cell cycle progression \\
\hline UBE2R2 & Classes III & Unknown & $\beta$-catenin degradation \\
\hline UBE2S & Classes III & $\begin{array}{l}\text { Cancer } \\
\text { Parkinson disease }\end{array}$ & Cell cycle progression \\
\hline UBE2T & Classes III & $\begin{array}{l}\text { Cancer } \\
\text { Fanconi anemia }\end{array}$ & DNA repair \\
\hline UBE2U & Classes III & Riddle's syndrome & DNA repair \\
\hline UBE2W & Classes I & Fanconi anemia & E2 for $\alpha$-amino group ubiquitination \\
\hline UBE2Z & Class IV & Coronary artery disease & FAT10 conjugation \\
\hline
\end{tabular}

Using immunohistochemical assays, it has been shown that expression levels of UBE2C protein are elevated in nasopharyngeal carcinoma tissues compared to benign nasopharyngeal tissues, which correlated with tumor size and metastasis. Moreover, expression levels of UBE2C negatively correlated with the degree of differentiation of nasopharyngeal carcinoma cell lines. Furthermore, silencing UBE2C led to cell cycle arrest at the $\mathrm{S}$ and $\mathrm{G} 2 / \mathrm{M}$ phases and reduced proliferation of undifferentiated C666-1 and poorly-differentiated CNE2Z nasopharyngeal carcinoma cells, but not immortalized NP-69 and well-differentiated CNE1 cells. These observations imply that overexpression of UBE2C in nasopharyngeal carcinoma is associated with cancer progression, which therefore makes UBE2C a suitable biomarker candidate for the progression, diagnosis, and treatment of nasopharyngeal carcinoma [53].

It has been suggested that evaluation of urinary UBE2C levels can be used for discriminating patients with bladder cancer from normal subjects with hematuria. Overexpression of UBE2C in bladder cancer is associated with advanced tumors, shorter cancer-specific survival, poor prognosis, and lymph vascular invasion [54]. The prognostic value of
UBE2C in bladder cancer has also been demonstrated in other studies $[55,56]$.

\subsection{UBE2D1 in cancer}

UBE2D consists of three main forms: UBE2D1, D2, and D3, which share $88 \%$ sequence homology and a similar enzymatic function. Dysregulation of UBE2D is involved in carcinogenesis as it promotes ubiquitination of the p53 protein [57,58]. Accordingly, silencing UBE2Ds upregulates p53, which is associated with increased apoptosis of human lung cancer cells [59]. Moreover, UBE2D4 (also known as HBUCE1) interacts with the E3 ubiquitin ligase CHIP and modulates cell cycle activities and proliferation of cancer cells [60]. Thus, targeting UBE2Ds can serve as a cancer immunotherapy strategy [61].

UBE2D1 can activate NF-kB and ubiquitinate stimulated receptorinteracting protein 1 (RIP1) in a TNF- $\alpha$ and cellular inhibitor of apoptosis protein 1 (c-IAP1)-dependent manner [62]. Blocking the interaction between UBE2D1 and Smad ubiquitination regulatory factor 2 (SMURF2) stabilizes Kirsten Ras (KRAS) and decreases cancer cell 


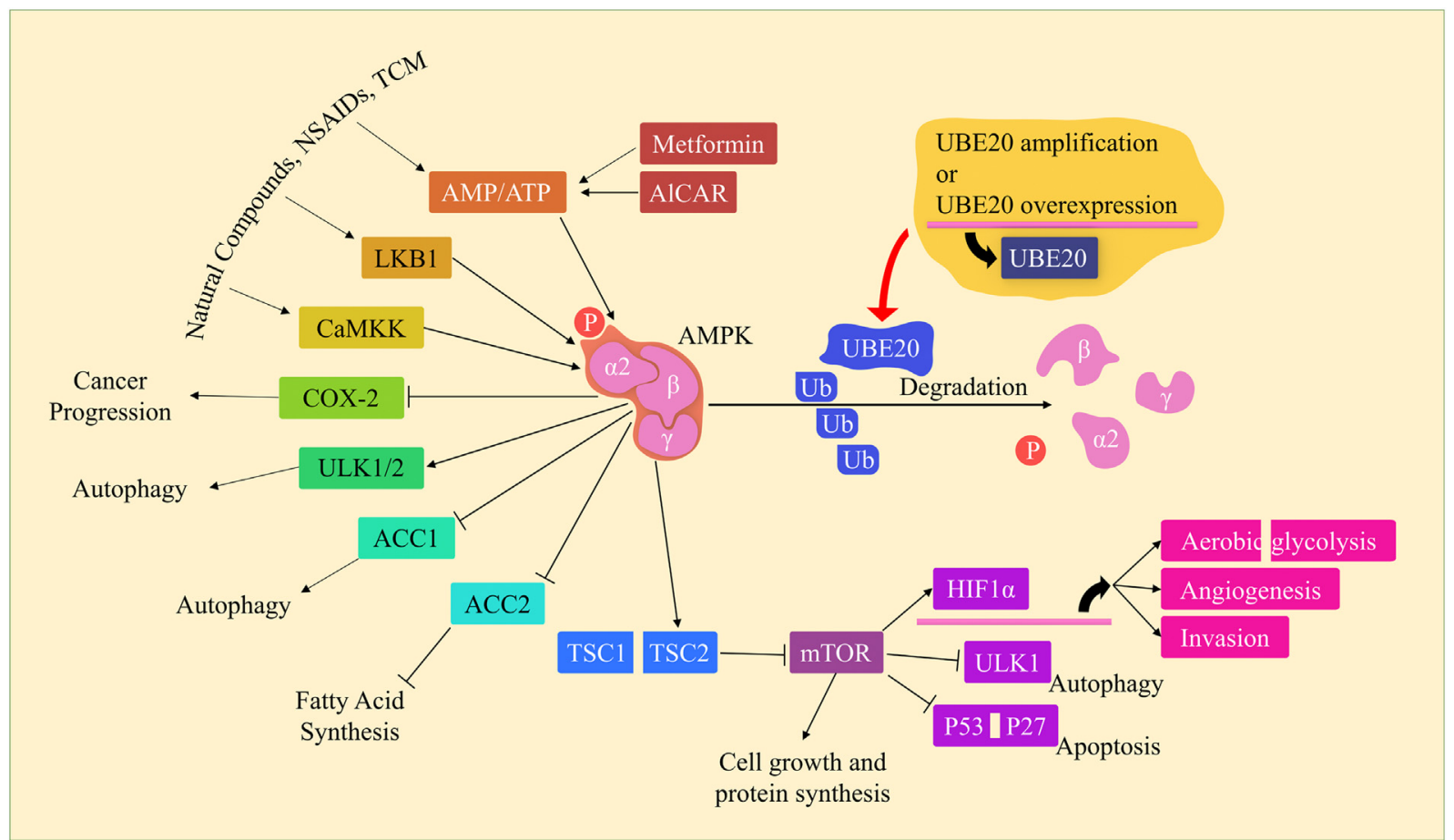

Fig. 2. NSAIDs, Natural products, TCM and metformin can activate AMPK. AMPK inhibits the mTOR pathway, leading to inhibition of cancer cell growth and proliferation. It can also suppress the pro-inflammatory enzyme COX-2, which is also involved in tumorigenesis. AMPK can induce the phosphorylation of tumor suppressor p53, resulting in cell cycle arrest. Activation of AMPK also enhances phosphorylation of ACC involved in metabolism of lipids. AMPK also prevents cancer progression through the anti-Warburg effect, cell cycle arrest, and suppression of EMT. UBE2O also promotes cancer progression by targeting AMPKa2 for ubiquitination and degradation, leading to induction of the mTOR-HIF-1 $\alpha$ pathway.

development in vitro and in vivo [63]. Inactivation of p53 robustly affects the development of lung adenocarcinoma [64]. UBE2Ds enhances DNA repair [65] and hence neutralize the DNA-damaging effects of chemotherapy or radiotherapy in cancer cells [66]. Accordingly, the overexpression of UBE2D1 has been shown to correlate with poor prognosis of lung adenocarcinoma [59].

Overexpression of UBE2D1 is also associated with recurrent genomic copy number gain and upregulation of IL-6 in hepatocellular carcinoma. Moreover, IL- 6 robustly enhanced growth of hepatocellular carcinoma partly by genomic gain of UBE2D1 and activation of the DNA damage response [67].

\subsection{UBE2E1 in cancer}

UBE2E1 can modulate the expression of HOX through the ubiquitination of histones [68]. Although the precise function of UBE2E1 is unknown, its regulatory impact on HOX expression can serve as a prognostic index for AML as dysregulation in the expression of HOX genes has been observed in AML patients [69,70].

\subsection{UBE2F in cancer}

Activated protein neddylation occurs in various cancerss. However, little is known regarding the role of UBE2F, a neddylation E2, in tumorigenesis. Overexpression of UBE2F has been observed in NSCLC, which was associated with poor patient survival. Moreover, UBE2F promotes cancer progression, which can be blocked by selective silencing techniques. UBE2F also promotes NOXA ubiquitination and proteasomal degradation by activating CRL5 (Cullin-RING-ligase-5) through CUL5 neddylation in a UBE2F/SAG/CUL5-dependent manner. Accordingly, the overexpression of UBE2F and CUL5 correlates with downregulation of NOXA and poor survival of lung cancer patients. These occurrences imply that UBE2F promotes lung cancer growth by ubiquitination and degradation of NOXA via CRL5 and thereby could serve as a cancer therapeutic target [71].

\subsection{UBE2I in cancer}

Activating mutations in the KRAS gene have been extensively observed in various cancers [72]. UBE2I (small ubiquitin-like modifier (SUMO) E2 ligase Ubc9) has been identified as KRAS lethal partner. UBE2I can regulate the stability and function of various proteins [73]. SUMOylation is pivotal for responses to cellular stresses, including genomic instability, DNA damage, and heat shock [74-76], indicating a role for this pathway and UBE2I in cancer progression. Consequently, targeting the SUMO pathway and UBE2I are potential therapeutic strategies for KRAS mutant colorectal cancer [77].

\subsection{UBE2J2 in cancer}

UBE2J2 is localized in the endoplasmic reticulum, it responds to proteotoxic stress and facilitates proteasomal degradation by interacting with ubiquitin ligases, such as parkin, CHIP, and TEB4 [78]. UBE2J2 also promotes TNF-R2-induced ubiquitination and degradation of TRAF2 through interaction with c-IAP1 [79]. UBE2J2 is involved in cancer cell invasion. Accordingly, overexpression of UBE2J2 has been detected in cell protrusions of HCCLM3 hepatocellular carcinoma cells [80]. However, further studies are required to understand the specific role(s) of UBE2J2 in promoting cancer progression.

\subsection{UBE2L6 in cancer}

The ubiquitin-like protein modifier, Interferon Stimulated Gene 15 (ISG15), can conjugate and regulate the function of protein substrates. ISG15 can conjugate protein substrates through the consecutive activity of E1, E2 and E3 enzymes. ISG15 and UBE2L6 have been identified as negative regulators of autophagy in esophageal cancer cells, which implies their involvement in cancer progression [81]. 


\subsection{UBE2O in cancer}

UBE2O, which can exert both E2 and E3 ligase activities, is involved in the endosomal trafficking of proteins [82], SMAD6 ubiquitination [83], and the cytoplasmic detention of nuclear BAP1 [84]. Increased expression of UBE2O has been demonstrated in various types of cancer [85-89]. UBE2O promotes cancer progression by targeting the AMPactivated protein kinase alpha 2 (AMPKa2) for ubiquitination and degradation, which leads to induction of the mTOR-HIF-1 $\alpha$ pathway. The stability and function of AMPK are important factors in cancer. Consequently, the expression and function of AMPK is decreased in multiple cancers including kidney, breast, ovarian, and gastric cancers [90,91]. AMPK can suppress tumor progression by various mechanisms such as inhibition of mTOR signaling, the anti-Warburg effect, cell cycle arrest, and inhibition of EMT [92,93]. Therefore, inhibition of UBE2O can suppress tumor development partly through the restoration of AMPKa2, which indicates that targeting the AMPKa2/UBE2O pathway can also serve as cancer therapeutic strategy [94].

IL-1 promotes the degradation of UBE2O and IRAK1/4 in normal cells. On the other hand, MLLs are resistant to degradation because they lack the MLL-UBE2O-binding site. Blockade of IRAK or UBE2O and concomitant proliferation of MLL leukemia cells has also been demonstrated $[95,96]$.

\subsection{UBE2Q1 in cancer}

Dysregulated expression of UBE2Q1 has been observed in several cancers including breast, colorectal, hepatocellular and ALL [97]. Accordingly, higher UBE2Q1 levels have been detected in cancerous tissues of hepatocellular carcinoma compared to adjacent normal tissues. Moreover, upregulation of UBE2Q1 significantly correlated with advanced stages of hepatocellular carcinoma and poor prognosis. Upregulated expression levels of UBE2Q1 were also detected in the serum of patients with hepatocellular carcinoma. Consequently, silencing UBE2Q1 by siRNA led to decreased proliferation, cell cycle arrest, and upregulation of p53 and p21 in BEL-7404 and HepG2 cells [98].

It has been proposed that UBE2Q1 can bind and suppress p53 expressed by breast cancer cells. Accordingly, transfection of MDA-MB468 breast cancer cells with the UBE2Q1-containing vector pCMV6-ANGFP was associated with downregulation of p53 and concomitant resistance to apoptosis. This indicates that UBE2Q1 increases the survival of cancer cells partly by ubiquitination of p53 and proteasome degradation [99].

Dysregulated expression of UBE2Q1 and UBE2Q2 has also been detected in colorectal cancer. The existence of $\mathrm{CpG}$ motifs in the loci of the UBE2Q1 and UBE2Q2 promoters, suggests that epigenetic changes may affect their expression levels. Consequently, the evaluation of the methylation status in the promoter regions of UBE2Q1 and UBE2Q2 genes expressed by tumor biopsies obtained from 60 patients with colorectal cancer showed differential methylation of both genes in cancer tissues compared to adjacent normal tissues. Results obtained showed that the UBE2Q2 promoter had a more unmethylated allele, whereas the UEBE2Q1promoter had more methylated allele in comparison to adjacent normal tissues [100].

\subsection{UBE2Q2 in cancer}

UBE2Q2, which is also known as UBCi, plays an important role in the progression of various cancers including head and neck squamous cell carcinoma. However, there is sparse knowledge regarding the mechanism(s), which underlie UBE2Q2-induced tumour development. The clue may lie in the expression of UBE2Q2 by human head and neck carcinoma cell lines and tumor biopsies. Studies have shown that some head and neck cancer (HNC) patients are resistant to CDDP (cis-diamminedichloroplatinum) or docetaxesome, which are therapeutics administered to HNC patients. Interestingly, the levels UBE2Q2 expressed by resistant cell lines and tumor biopsies were low., Moreover, forced expression of UBE2Q2 led reduced proliferation of cancer cells. These results imply that UBE2Q2 acts as an onco-suppressor, which can impact tumor growth and drug resistance. Consequently, UBE2Q2 can be considered as a novel theranostic factor in head and neck squamous cell carcinoma [101].

\subsection{UBE2S in cancer}

UBE2S is another E2 enzyme, which has been implicated in cancers including lung, brain, colon, cervix, thyroid, liver, nasopharynx, and breast cancer [102-105].

It has been demonstrated that silencing UBE2S in breast cancer cell lines can affect their morphology, survival and proliferation. UBE2S facilitates the exit of cells from the mitotic stage by the degradation of substrate proteins by $\mathrm{APC} / \mathrm{C}$ during mitosis via the proteasome pathway. Silencing UBE2S by siRNA molecules in MDA-MB-231 and BT20 (basal cell lines), and T47D and MCF7 cells (luminal cell lines) led to suppressed proliferation, increased apoptosis and changed morphology of cells, implying a role for UBE2S in tumorigenesis [106].

UBE2S can promote endometrial cancer through the UBE2S/SOX6/ $\beta$-Catenin pathway. Consequently the overexpression of UBE2S can enhance the migration and expansion of endometrial cancer cells, while silencing it reverses these effects. It has been observed that the upregulation of UBE2S in endometrial cancer cells promotes nuclear translocation of $\beta$-Catenin through suppression of SOX6 and upregulation of cyclin D1 and c-Myc. On the other hand, blockade of $\beta$-Catenin resulted in the inhibition of UBE2S-induced cancer cell expansion. Therefore, the components of the UBE2S-SOX6/ $\beta$-Catenin axis can serve as prognostic biomarkers and therapeutic targets of endometrial cancer [107].

Overexpression of UBE2S has also been observed in A549 lung adenocarcinoma cells, the lung cancer cell lines H1975, H1299, and95D and human lung cancer tissues, which was associated with poor prognosis. Knockdown of UBE2S in lung cancer cells correlated with reduced colony formation and proliferation, and increased apoptosis. UBE2S can regulate the expression of several genes involved in lung cancer, particularly p53 protein. Moreover, UBE2S can critically affect the growth and development of lung cancer [108].

Increased expression levels of UBE2S have been observed in highly invasive A431-III cells in comparison to A431-P, which negatively correlated with von Hippel-Lindau (VHL) and positively with HIF-1 $\alpha$. Silencing or overexpression of UBE2S demonstrated that it enhances the invasive and migratory characteristics of cancer cells via EMT signaling. Moreover, expression of UBE2S is significantly suppressed by luteolin and quercetin. These observations imply that UBE2S is involved in cervical cancer cell invasion and partly by HIF-1 $\alpha$ signaling, which can be blocked by luteolin and quercetin [4].

UBE2S can also serve as a prognostic factor of hepatocellular carcinoma as it contributes to tumorigenesis partly by the proteasomal degradation of p53. Consequently, overexpression of UBE2S enhanced the proliferation and migration of cancer cells, while silencing it inhibited these characteristics by targeting p53. On the other hand, the downregulation of UBE2S increased the expression of p53, p21 and cyclin D1 thereby suppressing cell proliferation. Therefore, UBE2S may be considered as an independent prognostic biomarker of hepatocellular carcinoma [109].

UBE2S increases the stability and cellular accumulation of $\beta$ Catenin by inhibiting its destruction. Moreover, UBE2S can enhance colorectal tumorigenesis in vitro and in vivo. Therefore, UBE2S promotes the malignancy of colorectal cancer by activating the Wnt/ $\beta$-Catenin signaling pathway [110].

\subsection{UBE2T in cancer}

UBE2T, which is also known as HSPC150, plays a key role in cell proliferation and the maintenance of chromosome stability through the 
ubiquitination of FANCD2. UBE2T implements a self-inactivation mono-ubiquitination process which can potentially induce negative regulation [111]. UBE2T is overexpressed in prostate cancer, promotes EMT and correlates with poor prognosis. It can enhance the proliferation, invasion and migration of cancer cells and promote tumor growth. Furthermore, the expression of UBE2T directly correlated with vimentin expression in prostate cancer [112]. Dysregulated expression of UBET2 has also been detected in prostate, lung, and bladder cancers [113,114]. Furthermore, UBE2T is located on chromosome 1q32.1; characteristic of several cancers, which indicates the oncogenic nature of this factor [115-118]. Hypoxia can reduce the expression UBE2T by cancer cell lines resulting in sensitization to chemotherapeutics, which further confirms the oncogenic potential of this factor [119]. The tumor induction by UBE2T has also been observed in nasopharyngeal carcinoma, by activation of the AKT/GSK3 $\beta / \beta$-catenin pathway [120]. The pro-tumor potential of UBE2T in hepatocellular carcinoma has been linked to the ubiquitination of p53 [121]. The correlation between UBE2T expression with poor clinical outcome has also been observed in multiple myeloma [122], melanoma [123], lung and breast cancer [124]. The overexpression of UBE2T has also detected in gastric tumor tissues, which correlated with poor prognosis [125]. In addition, ubiquitin-proteasome can affect gastric cancer by modulating the expression of oncogenes, tumor suppressor genes, and various signaling pathways [111].

Similar to other cancers, silencing UBE2T in osteosarcoma cells resulted in suppressed invasion, proliferation, and migration of cancer cells in a PI3K/Akt-dependent manner [126]. Knockdown of UBE2T also induced similar results in bladder [127] and gastric [128] cancer.

Hao and colleagues have demonstrated that UBE2T is overexpressed by lung cancer cell lines and biopsies from lung cancer patients, which was associated with poor prognosis [129]. The involvement of UBE2T in breast cancer progression through the interaction with BRCA1/ BARD1 complex and downregulation of BRCA1 has also been demonstrated [130]. This is mirrored by the dysregulated expression of UBE2T in breast cancer patients [131].

\section{Conclusion}

Despite several advances in the understanding of tumor immunobiology and the immunotherapy revolution, cancer treatment remains a major health challenge [132]. There are several hurdles in the journey to achieving an effective anti-cancer therapy [132,133]. The tumor microenvironment plays an important role in this predicament as it habours multiple cellular and non-cellular components which support tumor growth and suppress anti-tumor responses [132]. Ubiquitination, which is a hallmark of protein-degradation, has been identified as a pivotal factor involved in several functions such as DNA repair, transcription, recycling of cell membrane receptors, intracellular trafficking, endocytosis, angiogenesis and inflammatory signaling. Hence it is not surprising that their versatility corresponds with their ability to induce tumour formation and progression [30,57,91,94,121]. Amongst the ubiquitination-associated enzymes, E2s play a key role in carcinogenesis. This notion has been supported by various studies, in which high levels of various E2 enzymes have been observed in multiple cancers such as breast, colon, bladder, hepatocellular carcinoma, gastric, lung, cervix, nasopharyngeal carcinoma, and multiple myeloma $[3,41,45,55,91,101,123]$. E2 enzymes can promote tumorigenesis by different mechanisms. Furthermore, silencing their expression facilitates the suppression of cancer growth and development. Although these results substantiate their tumor-inducing properties, very few studies have targeted these factors in pre-clinical models. Moreover, data demonstrating the targeting of E2s in human cancer patients is sparse. There are a few E2 inhibitors available such as the Peptoid compound (Leucettamol A), Dimeric sterols (Manado sterols A and B), NSC697923, CC0651, and Triazines compounds [30], however, their specific functions and efficiency have not been demonstrated in human cancers. Nano-based drug delivery systems are promising tools for tumor-specific silencing of E2 enzymes, which should be considered in future studies [134-136]. Thus, further studies based on the development of potent anti-E2 therapeutics, are required to evaluate their efficacy as a cancer immunotherapy strategy.

\section{Acknowledgment}

None.

\section{Declaration of Competing Interest}

The authors declare no conflict of interest.

\section{References}

[1] A.C.A. Wan, Primitive cancer cell states: a target for drug screening? Trends Pharmacol. Sci. 40 (3) (2019) 161-171.

[2] J.A. Joyce, D.T. Fearon, T cell exclusion, immune privilege, and the tumor microenvironment, Science 348 (6230) (2015) 74-80.

[3] J. Zhang, X. Liu, G. Yu, L. Liu, J. Wang, X. Chen, et al., UBE2C is a potential biomarker of intestinal-type gastric cancer with chromosomal instability, Front. Pharmacol. 9 (2018) 847.

[4] T.-H. Lin, W.-H. Hsu, P.-H. Tsai, Y.-T. Huang, C.-W. Lin, K.-C. Chen, et al., Dietary Flavonoids, Luteolin and Quercetin, Inhibit Invasion of Cervical Cancer by Reduction of UBE2S Through Epithelial-Mesenchymal Transition Signaling, 8(4) (2017), pp. 1558-1568.

[5] Y. Yazdani, M. Mohammadnia-Afrouzi, M. Yousefi, E. Anvari, G. Ghalamfarsa, H. Hasannia, et al., Myeloid-derived suppressor cells in B cell malignancies, Tumor Biol. 36 (10) (2015) 7339-7353.

[6] G.P. Dunn, A.T. Bruce, H. Ikeda, L.J. Old, R.D. Schreiber, Cancer immunoediting: from immunosurveillance to tumor escape, Nat. Immunol. 3 (11) (2002) 991.

[7] L.A. Torre, F. Bray, R.L. Siegel, J. Ferlay, J. Lortet-Tieulent, A.J. Jemal, Global Cancer Statistics, 2012, 65(2) (2015), pp. 87-108.

[8] T.F. Gajewski, H. Schreiber, Y.-X. Fu, Innate and adaptive immune cells in the tumor microenvironment, Nat. Immunol. 14 (10) (2013) 1014.

[9] V. Hashemi, A. Masjedi, B. Hazhir-Karzar, A. Tanomand, S.S. Shotorbani, M. Hojjat-Farsangi, et al., The role of DEAD-box RNA helicase p68 (DDX5) in the development and treatment of breast cancer, J. Cell. Physiol. 234 (5) (2019) 5478-5487.

[10] D.F. Quail, J.A. Joyce, Microenvironmental regulation of tumor progression and metastasis, Nat. Med. 19 (11) (2013) 1423.

[11] A. Masjedi, H. Hassannia, F. Atyabi, A. Rastegari, M. Hojjat-Farsangi, A. Namdar, et al., Downregulation of A2AR by siRNA loaded PEG-chitosan-lactate nanoparticles restores the T cell mediated anti-tumor responses through blockage of PKA/CREB signaling pathway, Int. J. Biol. Macromol. 133 (Jul 15 2019) 436-445.

[12] A. Östman, The tumor microenvironment controls drug sensitivity, Nat. Med. 18 (9) (2012) 1332.

[13] S.M. Parizadeh, R. Jafarzadeh-Esfehani, S.M. Hassanian, S.M.R. Parizadeh, S. Vojdani, M. Ghandehari, et al., Targeting cancer stem cells as therapeutic approach in the treatment of colorectal cancer, Int. J. Biochem. Cell Biol. 110 (May 2019) 75-83.

[14] C. Belli, D. Trapani, G. Viale, P. D'Amico, B.A. Duso, P. Della Vigna, et al., Targeting the Microenvironment in Solid Tumors, 65 (2018), pp. 22-32.

[15] M. Haji-Fatahaliha, M. Hosseini, A. Akbarian, S. Sadreddini, F. Jadidi-Niaragh, M. Yousefi, CAR-modified T-cell therapy for cancer: an updated review, Artif. Cells Nanomed. Biotechnol. 44 (6) (2016) 1339-1349.

[16] R.A. Gatenby, R.J. Gillies, A microenvironmental model of carcinogenesis, Nat. Rev. Cancer 8 (1) (2008) 56.

[17] Y.J. Sun, Tumor Microenvironment and Cancer Therapy Resistance, 380(1) (2016), pp. 205-215.

[18] G. Ghalamfarsa, M.H. Kazemi, S. Raoofi Mohseni, A. Masjedi, M. Hojjat-Farsangi, G. Azizi, et al., CD73 as a potential opportunity for cancer immunotherapy, Expert Opin. Ther. Targets 23 (2) (2019) 127-142.

[19] G. Ghalamfarsa, A. Hadinia, M. Yousefi, F. Jadidi-Niaragh, The role of natural killer T cells in B cell malignancies, Tumor Biol. 34 (3) (2013) 1349-1360.

[20] N. Kheshtchin, S. Arab, M. Ajami, R. Mirzaei, M. Ashourpour, N. Mousavi, et al., Inhibition of HIF-1 $1 \alpha$ enhances anti-tumor effects of dendritic cell-based vaccination in a mouse model of breast cancer, Cancer Immunol. Immunother. 65 (10) (2016) 1159-1167.

[21] Z. Asadzadeh, H. Mohammadi, E. Safarzadeh, M. Hemmatzadeh, A. MahdianShakib, F. Jadidi-Niaragh, et al., The paradox of Th17 cell functions in tumor immunity, Cell. Immunol. 322 (2017) 15-25.

[22] A. Hershko, A. Ciechanover, H. Heller, A.L. Haas, I.A. Rose, Proposed role of ATP in protein breakdown: conjugation of protein with multiple chains of the polypeptide of ATP-dependent proteolysis, Proc. Natl. Acad. Sci. U. S. A. 77 (4) (1980) 1783-1786.

[23] C.M. Pickart, Mechanisms underlying ubiquitination, Annu. Rev. Biochem. 70 (2001) 503-533.

[24] D. Komander, M.J. Clague, S. Urbe, Breaking the chains: structure and function of the deubiquitinases, Nat. Rev. Mol. Cell Biol. 10 (8) (2009) 550-563. 
[25] C. Grabbe, K. Husnjak, I. Dikic, The spatial and temporal organization of ubiquitin networks, Nat. Rev. Mol. Cell Biol. 12 (5) (2011) 295-307.

[26] D. Popovic, D. Vucic, I. Dikic, Ubiquitination in disease pathogenesis and treatment, Nat. Med. 20 (11) (2014) 1242-1253.

[27] D. Komander, M. Rape, The ubiquitin code, Annu. Rev. Biochem. 81 (2012) 203-229.

[28] D. Hormaechea-Agulla, Y. Kim, M.S. Song, S.J.J.M. Song, New Insights Into the Role of E2s in the Pathogenesis of Diseases: Lessons Learned From UBE2O, 41(3) (2018), p. 168.

[29] M.D. Stewart, T. Ritterhoff, R.E. Klevit, P.S. Brzovic, E2 enzymes: more than just middle men, Cell Res. 26 (4) (2016) 423-440.

[30] X. Li, E. Elmira, S. Rohondia, J. Wang, J. Liu, Dou QPJEootp. A Patent Review of the Ubiquitin Ligase System: 2015-2018, 28(12) (2018), pp. 919-937.

[31] K.I. Nakayama, K. Nakayama, Ubiquitin ligases: cell-cycle control and cancer, Nat. Rev. Cancer 6 (5) (2006) 369-381.

[32] S.M. Molineaux, Molecular pathways: targeting proteasomal protein degradation in cancer, Clin. Cancer Res. 18 (1) (2012) 15-20.

[33] V. Ramatenki, S.R. Potlapally, R.K. Dumpati, R. Vadija, U. Vuruputuri, Homology modeling and virtual screening of ubiquitin conjugation enzyme E2A for designing a novel selective antagonist against cancer, J. Recept. Signal Transduct. Res. 35 (6) (2015) 536-549.

[34] A. Williamson, K.E. Wickliffe, B.G. Mellone, L. Song, G.H. Karpen, Rape MJPotNAoS. Identification of a Physiological E2 Module for the Human Anaphasepromoting Complex, 106(43) (2009), pp. 18213-18218.

[35] A. Matsumoto, Y. Ishibashi, M. Urashima, N. Omura, K. Nakada, K. Nishikawa, et al., High UBCH10 Protein Expression as a Marker of Poor Prognosis in Esophageal Squamous Cell Carcinoma, 34(2) (2014), pp. 955-961.

[36] S. Han, Q. Liu, Y. Yao, H. Sun, X. Zan, T. Song, et al., UbcH10 Expression in Hepatocellular Carcinoma and Its Clinicopathological Significance, 31(2) (2011), pp. 280-284.

[37] H. Kadara, L. Lacroix, C. Behrens, L. Solis, X. Gu, J.J. Lee, et al., Identification of Gene Signatures and Molecular Markers for Human Lung Cancer Prognosis Using an In Vitro Lung Carcinogenesis System, 2(8) (2009), pp. 702-711.

[38] T. Qin, G. Huang, L. Chi, S. Sui, C. Song, N. Li, et al., Exceptionally high UBE2C expression is a unique phenomenon in basal-like type breast cancer and is regulated by BRCA1, Biomed. Pharmacother. 95 (2017) 649-655.

[39] Y. Okamoto, T. Ozaki, K. Miyazaki, M. Aoyama, M. Miyazaki, A.J. Nakagawara, UbcH10 is the Cancer-related E2 Ubiquitin-conjugating Enzyme, 63(14) (2003), pp. 4167-4173.

[40] T. Fujita, H. Ikeda, N. Taira, S. Hatoh, M. Naito, H.J.B.C. Doihara, Overexpression of UbcH10 Alternates the Cell Cycle Profile and Accelerate the Tumor Proliferation in Colon Cancer, 9(1) (2009), p. 87.

[41] S. Chen, Y. Chen, C. Hu, H. Jing, Y. Cao, X.J.J. Liu, et al., Association of Clinicopathological Features With UbcH10 Expression in Colorectal Cancer, 136(3) (2010), pp. 419-426.

[42] J.H. Van Ree, K.B. Jeganathan, L. Malureanu, J.N.J.T. Van Deursen, Overexpression of the E2 Ubiquitin-conjugating Enzyme UbcH10 Causes Chromosome Missegregation and Tumor Formation, 188(1) (2010), pp. 83-100.

[43] P. Pallante, M. Berlingieri, G. Troncone, M. Kruhoffer, T. Orntoft, G. Viglietto, et al., UbcH10 Overexpression May Represent a Marker Of Anaplastic Thyroid Carcinomas, 93(4) (2005), p. 464.

[44] A. Psyrri, K. Kalogeras, R. Kronenwett, R. Wirtz, A. Batistatou, E. Bournakis, et al., Prognostic Significance of UBE2C mRNA Expression in High-risk Early Breast Cancer. A Hellenic Cooperative Oncology Group (HeCOG) Study, 23(6) (2011), pp. $1422-1427$.

[45] Z.-K. Zhao, W.-G. Wu, L. Chen, P. Dong, J. Gu, J.-S. Mu, et al., Expression of UbcH10 in Pancreatic Ductal Adenocarcinoma and Its Correlation With Prognosis, 34(3) (2013), pp. 1473-1477.

[46] T. Fujita, H. Ikeda, K. Kawasaki, N. Taira, Y. Ogasawara, A. Nakagawara, et al., Clinicopathological Relevance of UbcH10 in Breast Cancer, 100(2) (2009), pp. 238-248.

[47] A. Rawat, G. Gopal, G. Selvaluxmy, T.J. Rajkumar, Inhibition of Ubiquitin Conjugating Enzyme UBE2C Reduces Proliferation and Sensitizes Breast Cancer Cells to Radiation, Doxorubicin, Tamoxifen and Letrozole, 36(6) (2013), pp. $459-467$.

[48] C. Wang, Y.-H. Pan, M. Shan, M. Xu, J.-L. Bao, L.-M. Zhao, Knockdown of UbcH10 Enhances the Chemosensitivity of Dual Drug Resistant Breast Cancer Cells to Epirubicin and Docetaxel, 16(3) (2015), pp. 4698-4712.

[49] T.Z. Parris, A. Kovács, L. Aziz, S. Hajizadeh, S. Nemes, M. Semaan, et al., Additive Effect of the AZGP1, PIP, S100A8 and UBE2C Molecular Biomarkers Improves Outcome Prediction in Breast Carcinoma, 134(7) (2014), pp. 1617-1629.

[50] Y. Xiong, J. Lu, Q. Fang, Y. Lu, C. Xie, H. Wu, et al., UBE2C functions as a potential oncogene by enhancing cell proliferation, migration, invasion and drug resistance in hepatocellular carcinoma cells, Biosci. Rep. 39 (4) (Apr 17 2019) (pii: BSR20182384).

[51] J. Guo, D. Jin, Y. Wu, L. Yang, J. Du, K. Gong, et al., The miR 495-UBE2C-ABCG2/ ERCC1 axis reverses cisplatin resistance by downregulating drug resistance genes in cisplatin-resistant non-small cell lung cancer cells, EBioMedicine 35 (2018) 204-221.

[52] Y. Zhang, S. Tian, X. Li, Y. Ji, Z. Wang, C. Liu, UBE2C promotes rectal carcinoma via miR-381, Cancer Biol. Ther. 19 (3) (2018) 230-238.

[53] Z. Shen, X. Jiang, C. Zeng, S. Zheng, B. Luo, Y. Zeng, et al., High expression of ubiquitin-conjugating enzyme 2C (UBE2C) correlates with nasopharyngeal carcinoma progression, BMC Cancer 13 (2013) 192.

[54] T. Morikawa, T. Kawai, H. Abe, H. Kume, Y. Homma, M. Fukayama, UBE2C is a marker of unfavorable prognosis in bladder cancer after radical cystectomy, Int. J.
Clin. Exp. Pathol. 6 (7) (2013) 1367-1374.

[55] N. Fristrup, K. Birkenkamp-Demtroder, T. Reinert, M. Sanchez-Carbayo, U. Segersten, P.U. Malmstrom, et al., Multicenter validation of cyclin D1, MCM7, TRIM29, and UBE2C as prognostic protein markers in non-muscle-invasive bladder cancer, Am. J. Pathol. 182 (2) (2013) 339-349.

[56] W.T. Kim, P. Jeong, C. Yan, Y.H. Kim, I.S. Lee, H.W. Kang, et al., UBE2C cell-free RNA in urine can discriminate between bladder cancer and hematuria, Oncotarget 7 (36) (2016) 58193-58202.

[57] M.K. Saville, A. Sparks, D.P. Xirodimas, J. Wardrop, L.F. Stevenson, J.-C. Bourdon, et al., Regulation of p53 by the Ubiquitin-conjugating Enzymes UbcH5B/C In Vivo, 279(40) (2004), pp. 42169-42181.

[58] M. Tokumoto, Y. Fujiwara, A. Shimada, T. Hasegawa, Y. Seko, H. Nagase, et al., Cadmium toxicity is caused by accumulation of p53 through the down-regulation of Ube2d family genes in vitro and in vivo, J. Toxicol. Sci. 36 (2) (2011) 191-200.

[59] L. Hou, Y. Li, Y. Wang, D. Xu, H. Cui, X. Xu, et al., UBE2D1 RNA expression was an independent unfavorable prognostic indicator in lung adenocarcinoma, but not in lung squamous cell carcinoma, Dis. Markers 2018 (2018) 4108919.

[60] M. Kajiro, R. Hirota, Y. Nakajima, K. Kawanowa, K. So-ma, I. Ito, et al., The ubiquitin ligase CHIP acts as an upstream regulator of oncogenic pathways, Nat. Cell Biol. 11 (3) (2009) 312-319.

[61] V. Ramatenki, R. Dumpati, R. Vadija, S. Vellanki, S.R. Potlapally, R. Rondla, et al., Targeting the ubiquitin-conjugating enzyme E2D4 for cancer drug discovery-a structure-based approach, J. Chem. Biol. 10 (2) (2017) 51-67.

[62] E. Varfolomeev, T. Goncharov, A.V. Fedorova, J.N. Dynek, K. Zobel, K. Deshayes, et al., c-IAP1 and c-IAP2 are critical mediators of tumor necrosis factor alpha (TNFalpha)-induced NF-kappaB activation, J. Biol. Chem. 283 (36) (2008) 24295-24299.

[63] S. Shukla, U.S. Allam, A. Ahsan, G. Chen, P.M. Krishnamurthy, K. Marsh, et al., KRAS protein stability is regulated through SMURF2: UBCH5 complex-mediated beta-TrCP1 degradation, Neoplasia (New York, NY) 16 (2) (2014) 115-128.

[64] Y.H. Wu, T.C. Wu, J.W. Liao, K.T. Yeh, C.Y. Chen, H. Lee, p53 dysfunction by xeroderma pigmentosum group $\mathrm{C}$ defects enhance lung adenocarcinoma metastasis via increased MMP1 expression, Cancer Res. 70 (24) (2010) 10422-10432.

[65] C.K. Schmidt, Y. Galanty, M. Sczaniecka-Clift, J. Coates, S. Jhujh, M. Demir, et al., Systematic E2 screening reveals a UBE2D-RNF138-CtIP axis promoting DNA repair, Nat. Cell Biol. 17 (11) (2015) 1458-1470.

[66] N.J. Curtin, DNA repair dysregulation from cancer driver to therapeutic target, Nat. Rev. Cancer 12 (12) (2012) 801-817.

[67] C. Zhou, F. Bi, J. Yuan, F. Yang, S. Sun, Gain of UBE2D1 facilitates hepatocellular carcinoma progression and is associated with DNA damage caused by continuous IL-6, J. Exp. Clin. Cancer Res. 37 (1) (2018) 290.

[68] B. Zhu, Y. Zheng, A.D. Pham, S.S. Mandal, H. Erdjument-Bromage, P. Tempst, et al., Monoubiquitination of human histone H2B: the factors involved and their roles in HOX gene regulation, Mol. Cell 20 (4) (2005) 601-611.

[69] E. De Braekeleer, N. Douet-Guilbert, A. Basinko, M.J. Le Bris, F. Morel, M. De Braekeleer, Hox gene dysregulation in acute myeloid leukemia, Future Oncol. (London, England) 10 (3) (2014) 475-495.

[70] H. Luo, Y. Oin, F. Reu, S. Ye, Y. Dai, J. Huang, et al., Microarray-based Analysis and Clinical Validation Identify Ubiquitin-conjugating Enzyme E2E1 (UBE2E1) as a Prognostic Factor in Acute Myeloid Leukemia, 9(1) (2016), p. 125.

[71] W. Zhou, J. Xu, H. Li, M. Xu, Z.J. Chen, W. Wei, et al,, Neddylation E2 UBE2F Promotes the Survival Of Lung Cancer Cells by Activating CRL5 to Degrade NOXA via the K11 Linkage, 23(4) (2017), pp. 1104-1116.

[72] Y. Pylayeva-Gupta, E. Grabocka, D. Bar-Sagi, RAS oncogenes: weaving a tumorigenic web, Nat. Rev. Cancer 11 (11) (2011) 761-774.

[73] J.R. Gareau, C.D. Lima, The SUMO pathway: emerging mechanisms that shape specificity, conjugation and recognition, Nat. Rev. Mol. Cell Biol. 11 (12) (2010) 861-871.

[74] S.P. Jackson, D. Durocher, Regulation of DNA damage responses by ubiquitin and SUMO, Mol. Cell 49 (5) (2013) 795-807.

[75] M. Dasso, Emerging roles of the SUMO pathway in mitosis, Cell Div. 3 (2008) 5.

[76] F. Golebiowski, I. Matic, M.H. Tatham, C. Cole, Y. Yin, A. Nakamura, et al., System-wide changes to SUMO modifications in response to heat shock, Sci. Signal. 2 (72) (2009) ra24.

[77] B. Yu, S. Swatkoski, A. Holly, L.C. Lee, V. Giroux, C.-S. Lee, et al., Oncogenesis Driven by the Ras/Raf Pathway Requires the SUMO E2 Ligase Ubc9, 112(14) (2015), pp. E1724-E1733.

[78] U. Lenk, H. Yu, J. Walter, M.S. Gelman, E. Hartmann, R.R. Kopito, et al., A role for mammalian Ubc6 homologues in ER-associated protein degradation, J. Cell Sci. 115 (Pt 14) (2002) 3007-3014.

[79] C.J. Wu, D.B. Conze, X. Li, S.X. Ying, J.A. Hanover, J.D. Ashwell, TNF-alpha induced c-IAP1/TRAF2 complex translocation to a Ubc6-containing compartment and TRAF2 ubiquitination, EMBO J. 24 (10) (2005) 1886-1898.

[80] S. Chen, Y. Tan, H. Deng, Z. Shen, Y. Liu, P. Wu, et al., UBE2J2 Promotes Hepatocellular Carcinoma Cell Epithelial-mesenchymal Transition and Invasion In Vitro, 8(42) (2017), p. 71736.

[81] C.M. Falvey, T.R. O'Donovan, S. El-Mashed, M.J. Nyhan, S. O'Reilly, S.L.J.O. McKenna, UBE2L6/UBCH8 and ISG15 Attenuate Autophagy In Esophageal Cancer Cells, 8(14) (2017), p. 23479.

[82] Y.-H. Hao, J.M. Doyle, S. Ramanathan, T.S. Gomez, D. Jia, M. Xu, et al., Regulation of WASH-dependent Actin Polymerization and Protein Trafficking by Ubiquitination, 152(5) (2013), pp. 1051-1064.

[83] X. Zhang, J. Zhang, A. Bauer, L. Zhang, D.W. Selinger, C.X. Lu, et al., Fine-tuning BMP7 Signalling in Adipogenesis by UBE2O/E2-230K-mediated Monoubiquitination of SMAD6, 32(7) (2013), pp. 996-1007.

[84] N. Mashtalir, S. Daou, H. Barbour, N.N. Sen, J. Gagnon, I. Hammond-Martel, et al., 
Autodeubiquitination Protects the Tumor Suppressor BAP1 From Cytoplasmic Sequestration Mediated by the Atypical Ubiquitin Ligase UBE2O, 54(3) (2014), pp. 392-406.

[85] R. Briffa, I. Um, D. Faratian, Y. Zhou, A.K. Turnbull, S.P. Langdon, et al., Multiscale Genomic, Transcriptomic And Proteomic Analysis of Colorectal Cancer Cell Lines to Identify Novel Biomarkers, 10(12) (2015), p. e0144708.

[86] M. Lin, L. Smith, D. Smiraglia, R. Kazhiyur-Mannar, J. Lang, D. Schuller, et al., DNA Copy Number Gains in Head and Neck Squamous Cell Carcinoma, 25(9) (2006), p. 1424.

[87] K. Rice, X. Lin, K. Wolniak, B. Ebert, W. Berkofsky-Fessler, M. Buzzai, et al., Analysis of Genomic Aberrations and Gene Expression Profiling Identifies Nove Lesions and Pathways In Myeloproliferative Neoplasms, 1(11) (2011), p. e40.

[88] S. Toffoli, I. Bar, F. Abdel-Sater, P. Delrée, P. Hilbert, F. Cavallin, et al., Identification by Array Comparative Genomic Hybridization of A New Amplicon on Chromosome 17q Highly Recurrent in BRCA1 Mutated Triple Negative Breast Cancer, 16(6) (2014), p. 466

[89] X. Wang, X. Li, Y. Cheng, X. Sun, X. Sun, S. Self, et al., Copy Number Alterations Detected by Whole-exome and Whole-genome Sequencing of Esophageal Adenocarcinoma, 9(1) (2015), p. 22.

[90] S.M. Hadad, L. Baker, P.R. Quinlan, K.E. Robertson, S.E. Bray, G. Thomson, et al., Histological Evaluation of AMPK Signalling in Primary Breast Cancer, 9(1) (2009), p. 307.

[91] Y.H. Kim, H. Liang, X. Liu, J.-S. Lee, J.Y. Cho, J.-H. Cheong, et al., AMPKa Modulation in Cancer Progression: Multilayer Integrative Analysis of the Whole Transcriptome in Asian Gastric Cancer, 72(10) (2012), pp. 2512-2521.

[92] B. Faubert, G. Boily, S. Izreig, T. Griss, B. Samborska, Z. Dong, et al., AMPK is a Negative Regulator of the Warburg Effect and Suppresses Tumor Growth In Vivo, 17(1) (2013), pp. 113-124.

[93] D.G. Hardie, D.R.J.B. Alessi, LKB1 and AMPK and the Cancer-metabolism Link-ten Years After, 11(1) (2013), p. 36

[94] I.K. Vila, Y. Yao, G. Kim, W. Xia, H. Kim, S.-J. Kim, et al., A UBE2O-AMPKa2 Axis that Promotes Tumor Initiation and Progression Offers Opportunities For Therapy, 31(2) (2017), pp. 208-224.

[95] Z. Li, K. Younger, R. Gartenhaus, A.M. Joseph, F. Hu, M.R. Baer, et al., Inhibition of IRAK1/4 sensitizes T cell acute lymphoblastic leukemia to chemotherapies, J. Clin. Invest. 125 (3) (2015) 1081-1097.

[96] W. Rhyasen Garrett, L. Bolanos, J. Fang, A. Jerez, M. Wunderlich, C. Rigolino, et al., Targeting IRAK1 as a therapeutic approach for myelodysplastic syndrome, Cancer Cell 24 (1) (2013) 90-104.

[97] M.A. Fahmidehkar, S.M. Shafiee, E. Eftekhar, L. Mahbudi, A. Seghatoleslam, Induction of cell proliferation, clonogenicity and cell accumulation in S phase as a consequence of human UBE2Q1 overexpression, Oncol. Lett. 12 (3) (2016) 2169-2174.

[98] R. Chang, L. Wei, Y. Lu, X. Cui, C. Lu, L. Liu, et al., Upregulated expression of ubiquitin-conjugating enzyme E2Q1 (UBE2Q1) is associated with enhanced cell proliferation and poor prognosis in human hapatocellular carcinoma, J. Mol. Histol. 46 (1) (2015) 45-56.

[99] S.M. Shafiee, M. Rasti, A. Seghatoleslam, T. Azimi, A.A. Owji, UBE2Q1 in a human breast carcinoma cell line: overexpression and interaction with p53, Asian Pacific J. Cancer Prevent. 16 (9) (2015) 3723-3727.

[100] P. Mokarram, F. Shakiba-Jam, S. Kavousipour, M.M. Sarabi, A. Seghatoleslam, Promoter methylation status of two novel human genes, UBE2Q1 and UBE2Q2, in colorectal cancer: a new finding in Iranian patients, Asian Pacific J. Cancer Prevent. 16 (18) (2015) 8247-8252.

[101] H. Maeda, N. Miyajima, S. Kano, T. Tsukiyama, F. Okumura, S. Fukuda, et al., Ubiquitin-conjugating enzyme UBE2Q2 suppresses cell proliferation and is downregulated in recurrent head and neck cancer, Mol. Cancer Res. 7 (9) (2009) $1553-1562$.

[102] H. Aberle, A. Bauer, J. Stappert, A. Kispert, R. Kemler, beta-catenin is a target for the ubiquitin-proteasome pathway, EMBO J. 16 (13) (1997) 3797-3804.

[103] N.C. Ha, T. Tonozuka, J.L. Stamos, H.J. Choi, W.I. Weis, Mechanism of phosphorylation-dependent binding of APC to beta-catenin and its role in beta-catenin degradation, Mol. Cell 15 (4) (2004) 511-521.

[104] Y. Su, C. Fu, S. Ishikawa, A. Stella, M. Kojima, K. Shitoh, et al., APC is essential for targeting phosphorylated beta-catenin to the SCFbeta-TrCP ubiquitin ligase, Mol. Cell 32 (5) (2008) 652-661.

[105] G. Wu, G. Xu, B.A. Schulman, P.D. Jeffrey, J.W. Harper, N.P. Pavletich, Structure of a $\beta$-TrCP1-Skp1- $\beta$-catenin complex: destruction motif binding and lysine specificity of the SCFß-TrCP1 ubiquitin ligase, Mol. Cell 11 (6) (2003) 1445-1456.

[106] A.K. Ayesha, T. Hyodo, E. Asano, N. Sato, M.A. Mansour, S. Ito, et al., UBE2S is Associated With Malignant Characteristics Of Breast Cancer Cells, 37(1) (2016), pp. 763-772.

[107] M. Lin, T. Lei, J. Zheng, S. Chen, L. Du, H.J.T. Xie, et al., UBE2S Mediates Tumor Progression Via SOX6/ß-Catenin Signaling in Endometrial Cancer, (2019).

[108] Z. Liu, L.J. Xu, UBE2S Promotes the Proliferation and Survival Of Human Lung Adenocarcinoma Cells, 51(12) (2018), p. 642.

[109] Y.-H. Pan, M. Yang, L.-P. Liu, D.-C. Wu, M.-Y. Li, S.-G. Su, et al., UBE2S Enhances the Ubiquitination of p53 and Exerts Oncogenic Activities in Hepatocellular Carcinoma, 503(2) (2018), pp. 895-902.

[110] Z. Li, Y. Wang, Y. Li, W. Yin, L. Mo, X. Qian, et al., Ube2s Stabilizes $\beta$-Catenin Through K11-linked Polyubiquitination to Promote Mesendoderm Specification and Colorectal Cancer Development, 9(5) (2018), p. 456.

[111] Y.J. Machida, Y. Machida, Y. Chen, A.M. Gurtan, G.M. Kupfer, A.D. D'Andrea, et al., UBE2T is the E2 in the Fanconi Anemia Pathway and Undergoes Negative
Autoregulation, 23(4) (2006), pp. 589-596.

[112] M. Wen, Y. Kwon, Y. Wang, J.H. Mao, G. Wei, Elevated expression of UBE2T exhibits oncogenic properties in human prostate cancer, Oncotarget 6 (28) (2015) $25226-25239$

[113] T. Kikuchi, Y. Daigo, T. Katagiri, T. Tsunoda, K. Okada, S. Kakiuchi, et al., Expression profiles of non-small cell lung cancers on cDNA microarrays: identification of genes for prediction of lymph-node metastasis and sensitivity to anticancer drugs, Oncogene. 22 (14) (2003) 2192-2205.

[114] R. Takata, T. Katagiri, M. Kanehira, T. Tsunoda, T. Shuin, T. Miki, et al., Predicting response to methotrexate, vinblastine, doxorubicin, and cisplatin neoadjuvant chemotherapy for bladder cancers through genome-wide gene expression profiling, Clin. Cancer Res. 11 (7) (2005) 2625-2636.

[115] J.E. van der Wal, M.A. Hermsen, H.J. Gille, N.Y. Schouten-Van Meeteren, A.C. Moll, S.M. Imhof, et al., Comparative genomic hybridisation divides retinoblastomas into a high and a low level chromosomal instability group, J. Clin. Pathol. 56 (1) (2003) 26-30.

[116] D.M. Lillington, L.K. Goff, J.E. Kingston, Z. Onadim, E. Price, P. Domizio, et al., High level amplification of N-MYC is not associated with adverse histology or outcome in primary retinoblastoma tumours, Br. J. Cancer 87 (7) (2002) 779-782.

[117] S. Herzog, D. R. Lohmann, K. Buiting, A. Schuler, B. Horsthemke, H. Rehder, et al, Marked differences in unilateral isolated retinoblastomas from young and older children studied by comparative genomic hybridization, Hum. Genet. 108 (2) (2001) 98-104.

[118] D. Chen, B.L. Gallie, J.A. Squire, Minimal regions of chromosomal imbalance in retinoblastoma detected by comparative genomic hybridization, Cancer Genet. Cytogenet. 129 (1) (2001) 57-63.

[119] C.H.M.A. Ramaekers, T. van den Beucken, A. Meng, S. Kassam, J. Thoms, R.G. Bristow, et al., Hypoxia disrupts the Fanconi anemia pathway and sensitizes cells to chemotherapy through regulation of UBE2T, Radiother. Oncol. 101 (1) (2011) 190-197.

[120] W. Hu, L. Xiao, C. Cao, S. Hua, D. Wu, UBE2T promotes nasopharyngeal carcinoma cell proliferation, invasion, and metastasis by activating the AKT/GSK3beta/betacatenin pathway, Oncotarget 7 (12) (2016) 15161-15172.

[121] L.P. Liu, M. Yang, O.Z. Peng, M.Y. Li, Y.S. Zhang, Y.H. Guo, et al., UBE2T promote hepatocellular carcinoma cell growth via ubiquitination of p53, Biochem. Biophys. Res. Commun. 493 (1) (2017) 20-27.

[122] W. Zhang, Y. Zhang, Z. Yang, X. Liu, P. Yang, J. Wang, et al., High expression of UBE2T predicts poor prognosis and survival in multiple myeloma, Cancer Gene Ther. (Jan 9 2019), https://doi.org/10.1038/s41417-018-0070-x (Epub ahead of print).

[123] I. Gorlov, I. Orlow, C. Ringelberg, E. Hernando, M.S. Ernstoff, C. Cheng, et al., Identification of gene expression levels in primary melanoma associated with clinically meaningful characteristics, Melanoma Res. 28 (5) (2018) 380-389.

[124] J. Perez-Pena, V. Corrales-Sanchez, E. Amir, A. Pandiella, A. Ocana, Ubiquitinconjugating enzyme E2T (UBE2T) and denticleless protein homolog (DTL) are linked to poor outcome in breast and lung cancers, Sci. Rep. 7 (1) (2017) 17530.

[125] H. Yu, P. Xiang, Q. Pan, Y. Huang, N. Xie, W.J.T.B. Zhu, Ubiquitin-conjugating Enzyme E2T is an Independent Prognostic Factor and Promotes Gastric Cancer Progression, 37(9) (2016), pp. 11723-11732.

[126] Y. Wang, H. Leng, H. Chen, L. Wang, N. Jiang, X. Huo, et al., Knockdown of UBE2T inhibits osteosarcoma cell proliferation, migration, and invasion by suppressing the PI3K/Akt SIGNALING PATHWAY, Oncol. Res. 24 (5) (2016) 361-369.

[127] Y.Q. Gong, D. Peng, X.H. Ning, X.Y. Yang, X.S. Li, L.Q. Zhou, et al., UBE2T silencing suppresses proliferation and induces cell cycle arrest and apoptosis in bladder cancer cells, Oncol. Lett. 12 (6) (2016) 4485-4492.

[128] C. Luo, Y. Yao, Z. Yu, H. Zhou, L. Guo, J. Zhang, et al., UBE2T knockdown inhibits gastric cancer progression, Oncotarget 8 (20) (2017) 32639-32654.

[129] J. Hao, A. Xu, X. Xie, J. Hao, T. Tian, S. Gao, et al., Elevated expression of UBE2T in lung cancer tumors and cell lines, Tumour Biol. 29 (3) (2008) 195-203.

[130] T. Ueki, J.H. Park, T. Nishidate, K. Kijima, K. Hirata, Y. Nakamura, et al., Ubiquitination and downregulation of BRCA1 by ubiquitin-conjugating enzyme E2T overexpression in human breast cancer cells, Cancer Res. 69 (22) (2009) $8752-8760$.

[131] D. Colak, A. Nofal, A. Albakheet, M. Nirmal, H. Jeprel, A. Eldali, et al., Age-specific gene expression signatures for breast tumors and cross-species conserved potential cancer progression markers in young women, PLoS One 8 (5) (2013) e63204.

[132] F. Jadidi-Niaragh, G. Ghalamfarsa, M. Yousefi, M.H. Tabrizi, F. Shokri, Regulatory T cells in chronic lymphocytic leukemia: implication for immunotherapeutic interventions, Tumor Biol. 34 (4) (2013) 2031-2039.

[133] T. Kazemi, V. Younesi, F. Jadidi-Niaragh, M. Yousefi, Immunotherapeutic ap proaches for cancer therapy: an updated review, Artif. Cells Nanomed. Biotechnol. 44 (3) (2016) 769-779.

[134] H. Siahmansouri, M.H. Somi, Z. Babaloo, B. Baradaran, F. Jadidi-Niaragh, F. Atyabi, et al., Effects of HMGA 2 si RNA and doxorubicin dual delivery by chitosan nanoparticles on cytotoxicity and gene expression of HT-29 colorectal cancer cell line, J. Pharm. Pharmacol. 68 (9) (2016) 1119-1130.

[135] S. Sadreddini, R. Safaralizadeh, B. Baradaran, L. Aghebati-Maleki, M.A. Hosseinpour-Feizi, D. Shanehbandi, et al., Chitosan nanoparticles as a dual drug/siRNA delivery system for treatment of colorectal cancer, Immunol. Lett. 181 (2017) 79-86.

[136] M. Hosseini, M. Haji-Fatahaliha, F. Jadidi-Niaragh, J. Majidi, M. Yousefi, The use of nanoparticles as a promising therapeutic approach in cancer immunotherapy, Artif. Cells Nanomed. Biotechnol. 44 (4) (2016) 1051-1061. 